\title{
Hume's emotivist theory of moral judgements
}

\section{Correspondence:}

James Chamberlain, University of Nottingham, Department of Philosophy, University Park, Nottingham NG7 2RD, UK.

Email: james.chamberlain1@nottingham.ac.uk

\begin{abstract}
Hume is believed by many to hold an emotivist thesis, according to which all expressions of moral judgements are expressions of moral sentiments. However, most specialist scholars of Hume either deny that this is Hume's position or believe that he has failed to argue convincingly for it. I argue that Hume is an emotivist, and that his true arguments for emotivism have been hitherto overlooked. Readers seeking to understand Hume's theory of moral judgements have traditionally looked to the first section of Book 3 of his Treatise, which discusses the relation between morality and reason. I argue that there is evidence elsewhere which better supports Hume's emotivist thesis. Hume's arguments for emotivism focus more on the causes of moral sentiments than on their relation to reason or belief, and he argues that moral sentiments are such as to arise whenever we contemplate morally relevant objects. He also holds that the presence of moral sentiments precludes any possibility of moral belief, because moral beliefs could only be less vivid copies of moral sentiments, and these cannot simultaneously exist. Hume concludes that all moral judgements must be expressions of sentiments.
\end{abstract}

\section{Introduction}

Hume is undoubtedly, as Pigden claims, "widely regarded as the grandfather of emotivism and indeed of non-cognitivism in general' (Pigden, 2007 p. 199). Anyone, reading Hume for the first time, will be struck by language which seems to assert an emotivist thesis; one by which any expression of a moral judgement is purely the 
expression of an emotion. ${ }^{1}$ This certainly seems to be Hume's intention, for example, in the following paragraph:

To have the sense of virtue, is nothing but to feel a satisfaction of a particular kind from the contemplation of a character. The very feeling constitutes our praise or admiration. We go no farther; nor do we enquire into the cause of the satisfaction. We do not infer a character to be virtuous, because it pleases: But in feeling that it pleases after such a particular manner, we in effect feel that it is virtuous. (T 3.1.2.3, SBN $471)^{2}$

Yet many influential readers of Hume - Pigden included - do not understand him to be an emotivist. This is largely because Hume has yet to be accredited with any convincing arguments for this thesis. In the face of this lacuna, those who do see Hume as arguing for emotivism generally think he does so unsuccessfully, perhaps because he has not sufficiently distinguished emotivism from other, similar but incompatible theses (e.g. Flew 1966; Harrison 1976; Mackie 1980). Some commentators suggest that Hume is only concerned to argue that emotions have an important role in causing moral judgements, rather than to account for the semantics of such judgements, and that he therefore provides no considered semantic account (e.g. Árdal, 1966; Penelhum, 1975; Stroud, 1977). More recently, some intriguing arguments have been put forward to suggest that, despite passages which seem to assert an emotivist thesis, and despite the fact that Hume never talks of moral beliefs, he nevertheless understands some moral judgements to be beliefs (Garrett, 1997; Cohon, 2008). 
I believe that all these approaches are mistaken. Hume's theory is, I argue, an emotivist one, by which any expression of a positive moral judgement is purely an expression of 'approbation', while any expression of a negative moral judgement is one of disapprobation (T 3.1.2.3, SBN 471). His arguments for emotivism have, I suggest, been hitherto overlooked. Here, I aim to demonstrate where these arguments are to be found, and to show that Hume's emotivist thesis follows validly from conclusions which are mainly established prior to his explicit discussion of morality. I shall not consider the plausibility of Hume's premises or assess the merits of emotivism more generally. Nevertheless, given Hume's pivotal role in the history of these theories, it is important that we understand precisely what he was arguing for here, and why.

This is significant because a new interpretation of Hume generates an entirely new argument for emotivism. Hume does not, as is often thought, rely on an argument that moral judgements cannot be beliefs, because moral judgements directly motivate us, whereas reasoning and beliefs do not (e.g. Stroud, 1977 p. 173; Bricke, 1996 p. 14). This argument has been seen as problematic, at best, since at least Snare (1975). Instead, I aim to show that Hume's argument rests on his account of the nature and causes of the moral emotions, or 'sentiments' (T 3.1.2.1, SBN 470).

Hume uses this account to explain not only how we come to form moral judgements, but also why we generally mistake them for beliefs; something which is clearly highly unusual for a passionate reaction. Moral sentiments are 'calm' passions; ones which are more similar in their phenomenology to belief than to paradigm 'violent' - strongly felt - passions ( $\mathrm{T}$ 2.3.3.10, SBN 418). Few other passion kinds are typically calm, and Hume suggests that most of these are at least sometimes violent (T 2.3.3.9, SBN 417-8). However, he never mentions violent moral passions, and it is seemingly 
their consistent calmness which means that moral sentiments are consistently 'taken for the determinations of reason' ( $\mathrm{T}$ 2.3.3.8, SBN 417).

Hume's arguments for emotivism focus more on the causes of moral sentiments than on their relation to reason or belief. He argues that moral sentiments are such as to arise whenever we contemplate morally relevant objects. He also holds that the presence of moral sentiments precludes any possibility of moral belief, because moral beliefs could only be less vivid copies of moral sentiments, and these cannot simultaneously exist.

Three aspects of Hume's wider philosophy are crucial here; his theory of causal reasoning, his distinction between impressions and ideas, and his understanding of moral sentiments. Unfortunately, Hume never explicitly states his emotivist thesis in unambiguous terms. It will therefore be helpful to distinguish two key interpretative claims at the start, which I will argue for separately. These are as follows:

Hume's Emotivism 1 (HE1). Hume claims that every moral judgement about an object involves an occurrence of approbation or disapprobation, caused by that object.

Hume's Emotivism 2 (HE2). Hume implies that, whenever an object causes an occurrence of approbation or disapprobation, any moral judgement about that object will consist of nothing other than this approbation or disapprobation.

Together, HE1 and HE2 assert that Hume's is an emotivist theory of moral judgements. To justify this interpretation, I must focus some attention on his theories of ideas and of reasoning. Importantly, I will not deny that reasoning and beliefs have some place in 
forming moral judgements, by Hume's account. He claims that we feel approbation towards character traits which custom tells us are "naturally fitted to be useful to others, or to the person himself, or... agreeable to others, or to the person himself' (T 3.3.1.30, SBN 591). We can certainly use reasoning to determine if a certain trait is naturally fitted to be useful or agreeable in this way. Nevertheless, Hume holds that, once we do understand a trait as fitted to be useful or agreeable, we judge it to be virtuous only by feeling approbation towards it.

In the next section, I consider the most salient features of Hume's theory of the imagination: the derivation of ideas from impressions; reasoning; and belief. In Section 3, I look to recent interpretations of Hume to ask to what extent Hume's account of reasoning might provide evidence against the claim that his is an emotivist theory. In Section 4, I argue that Hume holds what I call the Causal Thesis. This states that wherever there is an impression or idea of a useful or agreeable character trait, a sentiment of approbation immediately occurs; and that wherever there is an impression or idea of a harmful or disagreeable character trait, a sentiment of disapprobation immediately occurs. We will see that this gives us HE1. In Section 5, I argue that Hume holds what I call the Vivacity Thesis. This states that wherever we have a present impression, we cannot hold an idea in mind which differs from that impression only in its level of vivacity. This gives us HE2. Together, HE1 and HE2 demonstrate Hume's emotivist thesis.

\section{Vivacity, reasoning and belief}

Hume begins his Treatise by considering the distinction between impressions and ideas. Impressions - roughly, our sense perceptions and feelings - are the most forceful and 
lively of our perceptions, and this is the feature that defines them (T 1.1.1.1, SBN 1). All ideas - roughly, our thoughts and memories - are caused by prior impressions and exactly resemble them, only except that ideas have lower degrees of 'vivacity' than impressions (T 1.1.1.3, SBN 2). Hume gives an example: 'That idea of red, which we form in the dark, and that impression, which strikes our eyes in sun-shine, differ only in degree, not in nature' (T 1.1.1.5, SBN 3). While Hume is unfortunately unclear exactly what terms like 'force', 'liveliness' and 'vivacity' are intended to mean, he clearly feels that the difference between the ways that impressions and ideas seem to us is of great importance.

I shall henceforth assume that all the terms in question refer to the same property, which I shall call 'vivacity'. Hume thinks that all impressions seem or feel more immediately real than any ideas or beliefs, although he does allow a 'near resemblance in a few instances' (T 1.1.1.1, SBN 2). Although detailed interpretations of vivacity vary, I take it that any increase in a perception's vivacity involves (or, perhaps, is) an increase in the extent to which it seems really present (e.g. Waxman, 1994; Dauer, 1999; Boehm, 2013). Impressions are maximally vivid, so that we take them to be immediately and presently real, rather than merely thought of or representative of something elsewhere, as we take ideas and beliefs to be.

Hume argues that ideas can be formed in two ways; as memories or as ideas of the imagination. These are distinguished primarily by degrees in vivacity. An idea is a memory idea if it immediately and directly retains some of the vivacity of an impression, so that it is 'somewhat intermediate betwixt an impression and an idea' in its level of vivacity (T 1.1.3.1, SBN 8). Presumably, Hume means it is intermediate between an impression and an imagined idea. Memories seem real to us from the moment they are formed, albeit in the past. All other ideas are formed as 'perfect' ideas; 
ones which are imagined, and which possess no vivacity (T 1.1.3.1, SBN 8). However, perfect ideas can be manipulated in ways that memory ideas cannot, including by reasoning. In this way, they can acquire vivacity, so that they become believed ideas, or beliefs (a belief simply is a vivid or believed idea for Hume). To see how ideas may become beliefs, we must consider Hume's account of reasoning.

Hume argues that there are only two forms of reasoning, both of which are performed by the faculty of the imagination. The first he calls 'demonstration', which consists of reasoning with 'the abstract relations of our ideas', as with mathematical or logical reasoning ( $\mathrm{T}$ 2.3.3.2, $\mathrm{SBN} 413$ ). The second consists of all 'reasonings from causation, and concerning matters of fact' (T 1.3.7.3, SBN 95). When Hume talks of beliefs, he officially refers only to the believed conclusions of causal reasoning. ${ }^{3}$ Hume defines a belief as a 'lively idea related to a present impression' (T 1.3.8.1, SBN 98), although this is shorthand for lively ideas related to impressions or memories ( $\mathrm{T}$ 1.3.5.7, SBN 86). Causal reasoning is, as we shall see, precisely the process by which ideas come to be lively, or vivid, in this way.

Causal reasoning is the product of two mental processes which are, for Hume, obviously prevalent in human psychology but ultimately inexplicable. These are the association of ideas and the transference of vivacity between perceptions. The first of these processes is described as the operation of 'a gentle force, which commonly prevails' whenever ideas are related by resemblance, contiguity in time or place, or cause and effect ( $\mathrm{T}$ 1.1.4.1, SBN 10). Causal relations occur wherever we have frequently seen one object follow another, so that we come to associate the two by custom or habit. If we have often seen smoke follow fire, then any new perception of fire - whether an impression or idea - will be followed by an idea of smoke. Ideas of fire follow perceptions of smoke too, as we can make inferences both from cause to 
effect and from effect to cause. The stronger the association, the more swiftly and easily the second idea occurs.

Even where ideas are strongly associated, this alone will not cause us to form beliefs. The second mental process required is the concurrent transference of vivacity from an impression or memory to an associated idea. If I see smoke rising over a distant hill, then the association of ideas between smoke and fire will impel me to form an idea of fire behind the hill. For me to believe this idea of fire, and thus to have reasoned that the smoke was caused by an unperceived fire, some of the vivacity of the perception of smoke must be transferred to the idea of fire. This is something which will naturally occur when the initial perception is an impression, so I will readily believe in the fire as a cause of the smoke, and as existing beyond my senses. In this way, causal reasoning is explained entirely by customary associations of ideas and the transference of vivacity.

Hume thinks that, although there is some possibility of error for any belief or memory, we cannot be mistaken about impressions. While one might think that we can be mistaken about sense impressions, if they fail to accurately represent aspects of the real world, Hume clearly distinguishes each impression from the belief about an object of 'real existence' which exists, as it were, 'behind' the impression (T 1.4.2.24, SBN 199). This belief can be false, but the impression is not truth-apt in this way. An impression is real simply in the sense that we are 'assur' $d$ of its present existence', just as we are assured that our ideas exist as ideas (T 1.3.8.15, SBN 106). If I see grey, swirling forms against a blue background then I am as certain of these perceptions as I can be about anything. Even if I simultaneously believe that I am hallucinating the sight of smoke, I am certain that I see what I see. The vivacity of any impression is of that impression simpliciter. It is not contingent on anything beyond the impression. 
We cannot be mistaken about impressions, simply because there is no possible world in which one can experience an impression and yet not experience it. In contrast, every causal belief and memory is such that there is a possible world where it is false. Indeed, a belief is only believed because of the relation of ideas between it and one's current impressions, and the vivacity that is thereby transferred to it from those impressions. Similarly, a memory's vivacity is always contingent on that of a former, now vanished, impression. All beliefs and memories are therefore subject to at least some uncertainty, although Hume allows that some beliefs are so well-evidenced that we do not doubt them in practice (T 1.3.11.2, SBN 124). For Hume, the relevant principle is what Garrett (2015 p. 48) calls his 'Conceivability Principle'; that 'nothing of which we can form a clear and distinct idea is absurd and impossible' (T 1.1.7.6, SBN 19-20). We can clearly imagine any causal belief or memory being false; therefore, we can never feel complete certainty about any belief or memory. We will see in Section 5 that this principle is of crucial importance to HE2.

This is merely a brief survey of Hume's accounts of vivacity, reasoning and belief, albeit of the most salient points. Hume claims that we typically or always form ideas from impressions, that the process of causal reasoning can give vivacity to these ideas, and that we believe those ideas which acquire a sufficient level of vivacity. Yet, if Hume's is an emotivist theory, as I argue, then he cannot allow that we believe any ideas derived from moral impressions. In the next section, I consider two arguments against the claim that Hume is an emotivist, which suggest that he does allow for moral beliefs, just as he allows that we can come to believe ideas derived from sense impressions. I then counter these by arguing that, for Hume, moral ideas cannot be believed in the way that ideas derived from sense impressions can be, because the operations of our passions preclude this. 


\section{Potential arguments against Humean emotivism}

Garrett (1997) and Cohon (2008) suggest two means by which Hume seems to allow moral beliefs to be formed. Cohon argues that we can form moral beliefs without inference, and I discuss this in 3.1. In 3.2, I discuss Garrett's claim that we can use reason to form moral beliefs.

Both Garrett and Cohon see an important parallel between Hume's accounts of sense impressions and moral impressions. Virtue, they suggest, is importantly similar to a sensory property like redness. We understand that an object looks red because we see it looking so, and we therefore form beliefs about unperceived red objects by having vivid ideas of them as having this unanalysable property. Similarly, they argue, we understand a character to be virtuous because it feels a certain way, so we can form beliefs about absent virtuous characters by forming vivid ideas of them with this unanalysable property.

In 3.3, I argue that Hume does not allow this parallel. To perceive something as red is just to have an impression of it as red, because Hume denies that colour and form arise from distinct impressions. Instead, we see impressions of colour 'dispos'd in a certain form' (T 1.1.7.18, SBN 25). My belief that a box is red just is a vivid idea of it as a box with that property I call redness. However, to take something to be virtuous is to experience approbation as caused by that object. I argue, therefore, that any belief that an object is virtuous could only be a belief that it is such as to cause approbation; not a belief that it has a certain quality. ${ }^{4}$

\subsection{Moral memories}


For Cohon (2008 p. 138), 'Hume's position is that ordinarily I acquire moral beliefs as the result of feeling a trait's goodness or evil - sensing the moral property directly - and then forming an idea-copy of my moral sentiment'. She argues for a direct comparison with beliefs about colour; 'normally I obtain my beliefs about what colors things are in response to a sensory experience' (Cohon, 2008 p. 104). If I see a red box, then Hume's account seems to suggest that I will form an idea-copy of its colour which, being vivid, will be a belief that the box is red. Surely, argues Cohon, Hume must allow that we similarly form beliefs directly from our moral sentiments. If I feel approbation towards someone, then presumably I will likewise form a vivid idea-copy of this approbation; a moral belief.

However, Hume does not allow that we form beliefs directly from impressions. He claims that we may form a vivid or a non-vivid idea-copy - or, more likely, both from any impression, but neither kind will be a belief. To form a vivid idea-copy is to have a memory. These can never be beliefs, because all beliefs exist within the faculty of the imagination, which is distinct from that of the memory (T 1.1.3.1, SBN 8). All ideas formed within the imagination are 'perfect', non-vivid ideas (T 1.1.3.1, SBN 8). Although we can later enliven these by causal reasoning, they begin as merely imagined ideas. Any beliefs about whether the objects which we perceive are 'really' of the colour they appear are formed by reasoning about the external world, as Hume argues in $\mathrm{T}$ 1.4.2. Therefore, we cannot directly form a belief from any impression, whether of a colour or a moral sentiment.

However, even if Cohon is describing what Hume would understand as moral memories rather than moral beliefs, she suggests a non-emotivist interpretation of his account of moral judgements. If I feel disapprobation towards Rousseau, then I judge 
him to be vicious. If I remember that I felt disapprobation towards Rousseau, then I have a vivid idea of his viciousness. In expressing this memory, I express my judgement of his viciousness, without any sentiment occurring. To defend HE1, therefore, I will have to demonstrate that Hume does not allow that memories could be moral judgements.

\subsection{Moral beliefs}

Garrett (1997) argues, like Cohon, that Hume must allow that we can form ideas from moral impressions, just as we do from sense impressions. He claims that we could therefore reason with these ideas, and thereby 'formulate propositional judgements or beliefs to the effect that a particular person is virtuous' (Garrett, 1997 p. 197). We are, Garrett suggests, particularly likely to engage in such reasoning where we are too distant from people for their characters to readily cause moral sentiments in us. $\mathrm{He}$ argues that denying that we can reason about the morality of distant people would be like claiming that we "could never infer that a box was red or square - say, as the result of someone else's testimony that it was' (Garrett, 1997 p. 200).

Garrett's (1997 p. 200) example is that someone could 'infer from the testimony of the New York Times that Mother Teresa is virtuous'. Of course, by any account, such a judgement will be caused to some extent by reasoning. There will be inferences to the effect that Mother Teresa is a real person, that the writer is reliable, and so on. However, Garrett's claim is that someone could form the judgement that Mother Teresa is virtuous by reason alone in this case. If so, then HE1 is false, because any judgement so formed would be purely a moral belief. 
This is possible, according to Garrett, because of Hume's account of abstract ideas, which is based on his denial of Locke's account of 'abstraction', and his preference for Berkeley's theory of abstract ideas. Hume claims that 'all general ideas are nothing but particular ones, annexed to a certain term, which gives them a more extensive signification, and makes them recal upon occasion other individuals, which are similar to them' (T 1.1.7.1, SBN 17). Garrett (1997 p. 104) calls the groups in which ideas are 'annexed to a term' 'revival sets'. Briefly, as impressions cause ideas to be formed, we frequently notice 'a resemblance' between certain ideas (T 1.1.7.7, SBN 20). We therefore apply the same name to these ideas and place them in the same revival set. Any idea in that revival set may then be brought to mind and, by standing for all the ideas within the set, will constitute our abstract idea of the object type in question. Any new idea sufficiently resembling ideas already in the set will be annexed to the same term and likewise placed in the revival set.

We form our revival set of 'virtue' by grouping together all and only those ideas of 'personal characteristics that produce immediate moral approbation' (Garrett, $1997 \mathrm{p}$. 197). Garrett argues that, once we have categorized a sufficient number of ideas in this way, we can form beliefs about appropriate new members of the set without feeling approbation, by noticing resemblances between these traits and ones previously classed as 'virtuous'. The reader of the New York Times understands that Mother Teresa has traits of a kind which she usually calls virtuous and so, without any sentiment necessarily occurring, she applies the term 'virtue' to the idea of Mother Teresa's character. She therefore believes that Mother Teresa is virtuous.

If moral reasoning of this kind is possible by Hume's account, as it currently seems to be, then what, precisely, is being believed about Mother Teresa at its conclusion? Garrett thinks the belief is that Mother Teresa's character has an 
unanalysable property; that what is believed 'can only be expressed by saying that she is virtuous' (Garrett, 1997 p. 202). In 3.3, I argue, against Garrett, that any such belief could only be that Mother Teresa's character is such as to cause approbation.

\subsection{The Vivid Idea of Virtue}

Any belief about virtue is, of course, a vivid idea of virtue. In the moral Enquiry, Hume 'defines virtue to be whatever mental action or quality gives to a spectator the pleasing sentiment of approbation' (EPM App. 1.10, SBN 289). His account in the Treatise is consistent with this definition (see particularly T 3.3.1.30, SBN 591). Therefore, any idea of a virtuous character trait just is a complex idea of both a mental action or quality and an associated sentiment of approbation. It is because we observe that some complex ideas resemble one another in this way that we form the revival set of 'virtue'. The idea of Mother Teresa's character could only be included, and so sincerely called 'virtuous', if it resembles other ideas of virtuous characters by bringing to mind a further idea of approbation. Therefore, the belief that Mother Teresa is virtuous is the belief that her character is such as to cause approbation.

Garret can resist this conclusion, because he claims that Hume allows two ways in which one can form the abstract idea of virtue, only one of which requires an idea of approbation. Garrett (1997 p. 107) argues that Hume defines 'personal merit' as the possession of traits which display 'usefulness or agreeableness to the possessor or others', and that, because all and only such mental qualities cause approbation, Hume considers this to be a definition of personal merit and of virtue. If so, then ideas of personal merit would also be ideas of virtue, but ones involving no ideas of approbation. 
However, Hume never claims that 'the possession of useful or agreeable mental qualities' is a definition of virtue. Garrett (1997 p. 107) only points to one passage to support this interpretation, where Hume says that every useful or agreeable trait 'communicates a pleasure to the spectator', and is then deemed virtuous (EPM 9.12, SBN 277). Yet this merely supports Hume's explicit definition of virtuous traits as ones which causes approbation. It is, for Hume, merely a contingent fact that all and only useful or agreeable traits cause approbation. The idea of virtue is of traits which cause approbation, although the same traits are also understood, by causal reasoning, to be useful and agreeable ones. Nevertheless, the abstract ideas of virtue and personal merit remain distinct; one could conceive of a useless, disagreeable virtue, simply by imagining such a trait causing approbation.

Therefore, any belief that a character is virtuous is, for Hume, a vivid idea of it as a potential cause of approbation. If the reader believes that Mother Teresa's character is virtuous - rather than just that the journalist at the New York Times approves of her then she must believe that Mother Teresa's character is one which she, the reader, associates with causing approbation. She need not realize that this is all that there is to virtue, of course. Equally, she might not realize that Mother Teresa's character is such as to cause a sentiment of approbation, because Hume allows that we frequently mistake calm sentiments for reasoned judgements (T 2.3.3.8, SBN 417). Nevertheless, whatever she takes approbation to be, she would certainly understand that a virtuous trait is one which would cause her to approve, if she were in a position to witness it.

Any such belief could only be formed by causal reasoning. To believe that Mother Teresa is virtuous is to have a vivid idea of approbation as caused by her character. This idea is believed because of the vivacity transferred to it, from the reader's impressions of the newspaper, via the idea of Mother Teresa's character. If 
Hume does allow for moral reasoning, then any moral belief so produced will be a belief that a person's character is such as to cause approbation or disapprobation in the right circumstances. We will see the importance of this in Section 5.

In summary, Cohon's and Garrett's accounts suggest that we can form moral judgements in the absence of sentiment, just as we form beliefs and memories about the colours of unperceived objects. I have argued that any beliefs so formed could only be inferred beliefs that a character (or action) is such as to cause approbation. At present, it seems that Hume can allow both beliefs of this kind and memories to be judgements of virtue. To see why Hume does not allow either, and so why HE1 is true, I argue that we must first look to his account of the relevant impressions; approbation and disapprobation. It is the causes of these impressions which are of most importance here.

\section{The Causal Thesis}

In this section, I argue that Hume holds what I call the 'Causal Thesis': Wherever there is an impression or idea of a useful or agreeable character trait, a sentiment of approbation immediately occurs; and wherever there is an impression or idea of a harmful or disagreeable character trait, a sentiment of disapprobation immediately occurs. For Hume, all moral judgements are about traits of these kinds and so, if he holds the Causal Thesis, then HE1 is true.

I interpret Hume to argue that, wherever we have any idea of a trait of a kind which typically causes pleasure to its possessor or to others, we habitually form an idea of the pleasure associated with that trait. (The same applies, mutatis mutandis, with ideas of typically harmful or disagreeable traits and pain). We will see that the idea of a generally useful or agreeable trait is a complex idea, combining an idea of a trait and an 
associated idea of pleasure. Useful and agreeable traits cause approbation where they please us by sympathy, and we can experience 'extensive sympathy' with even nonbelieved ideas of pleasure or pain ( $\mathrm{T}$ 3.3.1.23, SBN 586), as when we sympathize with the distress of an imagined speaker when reading inelegant writing (T 3.3.1.22, SBN 585). We will therefore sympathize with that idea of pleasure which partially constitutes an idea of a generally useful or agreeable trait, and experience approbation, even if none of the relevant ideas are believed. ${ }^{5}$

We should note that, if this is correct, then we could not perform any reasoning about a useful trait before a moral sentiment was caused by our perception of it. Hume believes that the relation of cause and effect obtains for mental items just as it does for physical ones, and 'has the same effect on the mind, whether the united objects be motives, volitions and actions; or figure and motion.' (T 2.3.1.17, SBN 406-7) Whatever rules apply to causation as it applies to physical objects, apply equally to it as it applies to mental objects. Hume provides a list of such 'general rules', the first of which is that 'cause and effect must be contiguous in space and time' ( $T$ 1.3.15.3, SBN 173). Of course, approbation cannot be contiguous in space with anything, but this is not a worry. Hume's general rules come before his later claim that most objects exist without being located anywhere in space. This applies to smells, sounds and of course to 'moral reflection[s]' ( $\mathrm{T}$ 1.4.5.10, SBN 236). Yet these objects are still able to stand in relations of cause and effect to other objects ( $\mathrm{T}$ 1.4.5.12, SBN 237). Therefore, they must be contiguous in time with their causes and effects. An idea of a useful trait causes pleasure, via a process of sympathy which seems 'instantaneous', and we then immediately experience approbation (T 2.1.11.3, SBN 317). Any idea of a useful trait therefore produces approbation at least as quickly as one could form a belief about it by any process of reasoning. 
Importantly, approbation will be caused by any perception of a useful or agreeable character trait, as we can see from the fact that it is a passion. Passions are quite unlike sense impressions in their causal origins. 'Original impressions or impressions of sensation are such as without any antecedent perception arise in the soul' (T 2.1.1.1, SBN 275). In contrast, passions are secondary impressions, which are 'such as proceed from some of these original ones, either immediately or by the interposition of its idea' (T 2.1.1.1, SBN 275). Passions are always caused by a prior perception, whether an impression or an idea, and they are classified by Hume according to the perception kind which causes them. For example: 'Desire arises from good consider'd simply, and aversion is deriv'd from evil.' (T 2.3.9.7, SBN 439)

Approbation and disapprobation are forms of pleasure and pain (T 3.1.2.3, SBN 471). They are therefore such as to be the causes of desires and aversions, as when we desire to perform an action because we approve of the idea of it. Hume notes that there are many different kinds of pleasures (and presumably also of pains), which may have 'only such a distant resemblance, as is requisite to make them be express'd by the same abstract term' (T 3.1.2.4, SBN 472). We have seen that approbation is precisely that passion which is caused by perceptions of useful or agreeable mental qualities ( $\mathrm{T}$

\subsubsection{0, SBN 590).}

As it is a secondary impression, approbation may be caused by impressions or ideas of useful or agreeable mental qualities (T 2.1.1.1, SBN 275). Because a useful or agreeable object is one which has a certain causal role, approbation cannot be caused by simple ideas, but only by complex ones. Any such idea will combine (at least) an idea of a person's character trait (here understood as a motivation to act in a certain way) and an idea of consequent pleasures for other people. We understand the motivations of other people by sympathy, and we also understand the pleasurable nature of the effects 
of such motivations on third parties by sympathy. However, we associate these two elements - the motivations or traits with their useful or agreeable effects - by custom. It is custom which has led me to believe that motivations to help other people 'benevolent' motives - cause happiness in other people. Therefore, any perception of a benevolent motive will bring to mind an idea of the happiness of others, because of the strong association of these two ideas. These two perceptions, related in this way, form the complex idea of a useful trait. Given Hume's definition of secondary impressions above, it seems that any such idea is sufficient to cause approbation.

Persson (1997 p. 195) notes that Hume's definition of secondary impressions entails that ideas 'in which belief is placed' can cause passions. As Persson (1997 p. 194) also notes, Hume explicitly claims at T 1.3.10.3 (SBN 119) that beliefs can cause passions. ${ }^{6}$ However, it is notable that Hume's definition of secondary impressions does not specify that they are only caused by impressions and believed ideas. Equally, we should note Hume's maxim, 'that no object is presented to the senses, nor image form'd in the fancy, but what is accompany'd with some emotion or movement of spirits proportion'd to it' (T 2.2.8.4, SBN 373). We should therefore, at least initially, understand Hume to mean that any idea of a generally useful trait will be sufficient to produce approbation. Custom ensures that every perception of a generally useful or agreeable trait will produce an idea of happiness. This second idea may or may not be believed, depending on whether or not sufficient vivacity is transferred to it. However, this transference of vivacity is a distinct process from the association of ideas, as we saw in Section 2. Therefore, because secondary impressions are seemingly caused by any relevant idea, we should expect approbation to be caused even by an idea of a fictitious, futile desire to help someone. This idea will habitually produce an idea of the 
potential beneficiary's happiness, which will please via extensive sympathy and cause approbation.

Hume's description of the moral sentiments themselves supports this. Towards the end of the Treatise he describes approbation as the passion caused by every mental quality which 'gives pleasure by the mere survey' (T 3.3.1.30, SBN 591; see also T 3.1.2.11, SBN 475). As Penelhum (1975 p. 138) notes, this suggests that they please 'in themselves rather than in relation to ourselves'. Indeed, to give pleasure in this way surely involves pleasing regardless of any related causes or effects, whether to ourselves or to others. Surely Hume does not mean us to understand the 'mere survey' of a quality as the act of engaging in causal reasoning about that token quality's particular effects. It does, however, seem plausible that 'merely' surveying a mental quality involves categorizing it within a relevant revival set; as an instance of 'benevolence', for example. If so, then Hume seems to suggest that we approve of this token quality simply because we generally associate benevolence with causing happiness to others.

In the same passage, Hume claims that virtuous traits are those which are 'naturally fitted' to be useful or agreeable (T 3.3.1.30, SBN 591). Again, this strongly suggests that virtuous traits are ones which are generally useful or agreeable; ones which are known to be of a kind which causes happiness to others, ceteris paribus. As an analogy, we understand wood to be 'naturally fitted' to catch fire, even where dampness prevents a particular log from lighting. Given this, the claim that approbation is caused by the mere survey of a trait when it is 'naturally fitted' to be useful or agreeable seems to be the claim that any token perception of a generally useful or agreeable type of trait will cause approbation.

There is strong textual evidence, from Hume's account of the moral sentiments as secondary impressions, that he holds the Causal Thesis. If we are to understand that 
Hume thinks we can have an idea of a useful or agreeable trait without feeling approbation, we would need some textual evidence that this is the case. In 4.1, I consider and reject potential evidence arising from Hume's account of belief. In 4.2, I consider and reject potential evidence arising from cases where we feel opposing passions. 4.3 considers the implications of this thesis.

\subsection{The Causal Thesis: Implications of belief}

One might doubt that many unbelieved ideas could cause sentiments on Hume's account, because he holds belief to be 'almost absolutely requisite to the exciting our passions' (T 1.3.10.4, SBN 120). However, this clearly does not rule out that passions can be 'excited' by unbelieved ideas. Equally, Hume is discussing the relation between beliefs and actions in this section, and it is not clear that 'exciting' a passion is the same as causing one. His point is that unbelieved ideas rarely produce strong enough passions to cause actions, not that only beliefs can cause passions.

More importantly, Hume is explicit that some passions are caused by unbelieved ideas, particularly moral passions, as caused by perceptions of generally useful character traits:

These passions are mov'd by degrees of liveliness and strength, which are inferior to belief, and independent of the real existence of their objects. Where a character is, in every respect, fitted to be beneficial to society, the imagination passes easily from the cause to the effect, without considering that there are still some circumstances wanting to render the cause a compleat one. General rules create a species of probability, which 
sometimes influences the judgment, and always the imagination. (T

\subsubsection{0, SBN 585)}

Hume's argument is precisely that, even where we do not believe that a generally useful trait will be useful on a token occasion, the idea of its utility - an idea which is produced because we habitually associate the trait with an idea of the happiness of others - is sufficient to cause at least some approbation. Hume argues that this explains our approval of people who are motivated to help others, but are prevented by doing so by circumstances (T 3.3.1.19, SBN 584). Not only does approbation occur in such cases, but also, importantly, it constitutes a judgement that the trait is virtuous.

\subsection{The Causal Thesis: Implications of opposing passions}

A second potential reason to reject the Causal Thesis would be if Hume allowed that contrary causes sometimes prevent moral impressions from being caused by perceptions of useful or harmful traits. Just as the presence of water prevents the striking of a match from producing fire, there may be objects which can come before the mind and prevent ideas of useful or agreeable traits from producing approbation. The only objects which may be potentially such as to oppose passions are other passions. 'Nothing can oppose or retard the impulse of passion, but a contrary impulse', and all such contrary impulses will themselves be passions (T 2.3.3.4, SBN 415).

In this context, these may be self-interested passions, or passions felt towards certain individuals which bias us, usually due to variations in sympathy. Hume allows that such passions may oppose our moral judgements so that, for example, we can feel a self-interested pleasure at a motive which we would normally judge to be vicious. He 
tells us that, in such cases, people nevertheless form consistent moral judgements by taking a 'common point of view, from which they might survey their object, and which might cause it to appear the same to all of them' (T 3.3.1.30, SBN 591). We can be pleased by an action and simultaneously judge it as vicious.

This is a notorious wrinkle in Hume's account, and there are many theories about what precisely Hume thinks it means to take up this common or 'general' point of view (T 3.3.1.15, SBN 581). I do not want to fully enter this debate here, but only to consider Hume's understanding of the moral judgements which are formed in the face of opposing, partial passions. Does he believe that moral sentiments are prevented from occurring in such situations, due to the presence of opposing passions? If so, then presumably we make moral judgements from the common point of view by means of an inference about the judgement which we would usually make, were we not distracted by such passions. Alternatively, does Hume believe that moral sentiments still occur in such cases, but are rendered motivationally ineffective? By this account, we would be led by our approbation to call an action 'virtuous', even as we are led by partial feelings to be displeased by it.

Cohon (2008 p. 139) argues that judgements from the common point of view are caused by opposing sentiments, not by inference, so that we correct violent and selfinterested passions by feeling an opposing but calm moral passion. Something like this must be the case, because Hume firmly stresses that judgements made from the common point of view are matters of feeling. He begins his discussion of this viewpoint with the following claim:

The approbation of moral qualities most certainly is not deriv'd from reason, or any comparison of ideas; but proceeds entirely from a moral 
taste, and from certain sentiments of pleasure or disgust, which arise upon the contemplation and view of particular qualities or characters $(\mathrm{T}$ 3.3.1.15, SBN 581).

Later, he says that considering matters from the common point of view is the only way to 'produce that particular feeling or sentiment, on which moral distinctions depend' ( $\mathrm{T}$ 3.3.1.30, SBN 591). This is precisely what we would expect, given that approbation and disapprobation are by definition felt towards traits when they are considered in general. Taking the common or general point of view involves considering whether someone's character is naturally fitted to be useful or harmful; agreeable or disagreeable. Wherever it is any of these, a moral sentiment occurs.

We must conclude that Hume allows that any idea of a useful or agreeable trait will cause approbation, even where we also feel violent, unpleasant passions towards it. Partial passions may oppose moral ones, but only by causing an opposing motivating force. They do not prevent moral sentiments from occurring or from having some motivational force.

\subsection{Implications of the Causal Thesis}

We saw in Section 3 that the most plausible interpretations of Hume as allowing for non-sentimental moral judgements rely on an analogy between moral sentiments and sense impressions. This analogy suggests an argument that, because we form ideas from both kinds of impression, we can therefore believe or remember either kind of idea in the absence of the relevant impressions. Just as ideas derived from sense impressions can be judgements about unperceived objects, so too can ideas derived from moral 
sentiments be judgements about virtue and vice. However, the Causal Thesis shows a crucial difference in the causes of each kind of impression. This has important implications for any account of moral reasoning.

Whereas sense impressions cannot be caused by ideas, a sentiment of approbation can - and will - be caused by any idea of a useful or agreeable character, action or sentiment. Indeed, Hume's theories of secondary impressions and of custom entail that, even if I were told only that someone was virtuous, with no detail about their character beyond this, I would form a general idea of their possessing useful or agreeable character traits, and would therefore feel approbation. Hume argues that we all 'implicitly' maintain a belief that virtuous traits are ones which cause happiness to others (EPM 9.2, SBN 269). This is presumably because the causal relation between utility and approbation is so strong that we are able to make the inference from one to the other without even considering the matter. Where we have frequently experienced causal relations, 'the understanding or imagination can draw inferences from past experience, without reflecting on it' (T 1.3.8.13, SBN 104). Any persuasive testimony to the effect that someone is virtuous will cause me to infer the belief that they possess character traits which are naturally fitted to be useful or agreeable. As all perceptions of such traits cause approbation, this belief will cause approbation.

On Hume's account, therefore, reasoning about virtue is in all cases redundant, because whenever we have an idea of a useful or agreeable trait we will judge it as virtuous simply by experiencing approbation. After all, why reason with those ideas derived from our sense impressions? Only because sense impressions of the relevant kinds are frequently absent when we consider their causes and effects. In contrast, Hume thinks we need never reason about the causes of our passions because, wherever 
we consider the usual causes of a passion, we will feel some degree of the passion in question.

This is similar to a point which Blackburn (1993) makes about the disanalogies between colour perceptions and moral feelings, regarding the corrections we may wish to make to our judgements about these. I may be confused about the morality of an action because my selfish interests are affecting my judgement, just as I may be confused about the colour of an object because of bad lighting. However, Blackburn notes that the differences are crucial:

In the latter case we have only a judgement about what we would perceive were the light different. We do not have another colour perception alongside whatever we are seeing at the time. Whereas in the ethical case, we do have a genuinely moral sentiment emerging from the process, another original existence to put alongside whatever initial sentiment selflove generated. (Blackburn, 1993 p. 275)

We can transpose this thinking to the question of reasoning about the virtue of others. If I am told by a reliable witness that they passed a letter box, then I can infer that it is red, but I cannot see its redness. However, if a reliable witness tells me that a person helps others, then I have no need to infer that this person is virtuous, for the idea of helping others causes approbation. Equally, if they persuade me simply that a person is virtuous, then I will form a belief that their character is useful or agreeable. Again, this belief will cause approbation.

Hume's Causal Thesis demonstrates the truth of HE1: Hume claims that every moral judgement involves an occurrence of approbation or disapprobation. This is 
because we experience at least one such sentiment whenever any morally relevant idea comes to mind. Equally, the Causal Thesis demonstrates that reasoning about the morality of unperceived objects is simply not necessary in the way that reasoning about colour often is. However, this is not sufficient to demonstrate Hume's emotivism. Hume's claim is that we never form reasoned moral judgements; that every judgement of virtue is 'nothing but' a sentiment (T 3.1.2.3, SBN 471). Even given the Causal Thesis, we could hold a belief about Mother Teresa's virtue whilst simultaneously feeling approbation towards her. Indeed, Garrett (1997 p. 198) suggests that we may have a moral belief and a 'corresponding moral feeling' simultaneously. To show that Hume denies this possibility, and therefore that HE2 is true, we must consider his account of vivacity once more.

\section{The Vivacity Thesis}

The Vivacity Thesis states that, wherever we have a present impression, we cannot hold an idea in mind which differs from that impression only in its level of vivacity. Therefore, we cannot form a belief about a moral sentiment which, aside from its level of vivacity, is identical to a present moral sentiment. Unless Hume allows that a moral judgement could exist without either an impression or a vivid idea of approbation or disapprobation - a suggestion for which there is no textual evidence - this thesis demonstrates the truth of HE2.

Admittedly, Hume never explicitly states the Vivacity Thesis. It is however entailed by a small number of key claims in Book 1. First, any idea of $\mathrm{X}$ is identical to an impression of X, except that it is less vivid. We saw in Section 2 that Hume claims this of impressions and ideas of a particular shade of red, and he argues that 'the case is 
the same with all our simple impressions and ideas.' (T 1.1.1.5, SBN 3) Hume allows that there is more than one 'kind of approbation', but only where different kinds of useful and agreeable traits cause variation in the feeling of approbation (T 3.3.4.2, SBN 608). Therefore, any believed idea of approbation as caused by an object would be identical to, except less vivid than, an impression of approbation as caused by the same object.

Second, Hume says that 'every distinct perception, which enters into the composition of the mind, is a distinct existence, and is different, and distinguishable, and separable from every other perception, either contemporary or successive' ( $\mathrm{T}$ 1.4.6.16, SBN 259). If I believe that a box looks red, at the same time that I see it looks red, then I must be able to distinguish between my impression of red and my vivid idea of red. I would only be able to distinguish these perceptions by their differing levels of vivacity, as they are otherwise identical.

Third, Hume claims that we cannot doubt the existence of our perceptions, because they are 'immediately present to us by consciousness' (T 1.4.2.47, SBN 212). We can confuse one kind of perception for another, as when we confuse a calm passion for a reasoned belief, but we cannot doubt that the perception exists. If I believe that a box looks red, at the same time as I see that it looks red, then I must be able to identify that I have two perceptions of redness, which are distinguishable only by their differing levels of vivacity.

With this in mind, recall from Section 2 that all impressions are maximally vivid, whereas no beliefs are. If I see a box and have an impression of red, then I am certain that I see red; I know I cannot be mistaken here. If I believe that a box looks red, then, by definition, I am uncertain that I would see red when looking at it; I recognize some possibility of error. To be clear, the belief in question is not that the box is always 
or really red. It is simply a belief that the box looks red. If I were to maintain this belief at the same time as I look at the box and see its redness, then I would be in a state of both certainty and uncertainty about what is otherwise the exact same judgement about the box's redness. Given that this is impossible, Hume must hold the Vivacity Thesis.

For sense impressions, this has only a limited effect. I cannot form a belief that a box looks red while I see that it does, simply because at that time I know that it looks red. However, if the box is removed from my sight, then the impression of red is gone, and I can remember the box's redness, and form beliefs about its redness. For moral impressions, however, the case is different.

We saw in 3.2 that any belief that Mother Teresa is virtuous would be a vivid, complex idea of her character and of approbation as caused by it; a belief that her character would cause approbation in the right circumstances. The Causal Thesis entails that, if I read in the New York Times that Mother Teresa possesses any useful or agreeable traits, then I will immediately feel approbation. Equally, if it reports simply that she is virtuous, then I will habitually form an idea of her as possessing useful or agreeable traits, which will cause approbation. If I do not believe that Mother Teresa possesses the traits which I read about, then I will merely experience approbation towards the general ideas of the traits; I will consider them virtuous but not applicable to Mother Teresa. If, however, I infer that Mother Teresa does have such traits, then this approbation will be caused by what I believe to be her traits. It will be a judgement of her virtue.

This impression of approbation as caused by the idea of Mother Teresa's character will be identical to any believed idea of such approbation, except in its level of vivacity. The Vivacity Thesis entails that I cannot simultaneously experience these two perceptions. Therefore, I can never simultaneously experience the vivid idea of 
Mother Teresa's useful or agreeable traits and the vivid idea of a consequent approbation, because the former idea immediately causes approbation. As any belief about Mother Teresa's virtue could only consist of two such vivid ideas held together, I cannot form the belief that she is virtuous. In other words, I cannot merely believe that approbation is caused by a character while approbation is caused by it, any more than I can merely believe that I see a box as red while I see its redness. Similar arguments apply to all potential beliefs about virtue or vice. Therefore, the Causal Thesis and Vivacity Thesis together demonstrate that we cannot ever hold beliefs about virtue or vice. As such, Hume's is a non-cognitivist account; at least, to the extent that one's own moral judgements of right and wrong cannot be beliefs.

Equally, moral judgements cannot consist of memories of moral properties, as Cohon's interpretation suggests. In fact, we cannot ever form memory ideas of the virtuousness or viciousness of characters. Like beliefs, memory ideas are vivid, but less so than the otherwise identical impressions from which they are derived. Therefore, the Vivacity Thesis demonstrates that any memory idea of the viciousness of Rousseau's ingratitude can only be formed once I have ceased to feel disapprobation. The Causal Thesis demonstrates that, if I remember Rousseau's ingratitude, I will once again feel disapprobation.

Of course, we might wonder whether human nature is as consistent as Hume assumes. Might someone possess the capacity for sympathy or sentiment only to the extent that immediate experiences of relevant traits and their consequences produce moral sentiments, while ideas and memories of these do not ${ }^{7}$ Such a person might read of Mother Teresa's generosity or remember Rousseau's ingratitude, believe that these traits would cause her to feel moral sentiments under relevant conditions, but experience no sentiment. Given our understanding of the diverse nature of human psychology, 
including conditions like autism, this diversity of feeling seems plausible. Hume, however, sees sentiment as ubiquitous across all experience, to the extent that 'almost every kind of idea is attended with some emotion, even the ideas of number and extension, much more those of such objects as are esteem'd of consequence in life' ( $T$ 2.2.10.9, SBN 393). Given the foregoing arguments, therefore, we must conclude that Hume understands that anyone will experience a moral sentiment when they form an idea or memory of a relevant character trait. This allows for no situation in which one can form a vivid idea of one's own approbation or disapprobation as caused by any object. As ideas of this kind are the only plausible candidates, other than moral sentiments, for forming moral judgements, Hume's is an emotivist theory of moral judgements.

It is notable that, while the Vivacity Thesis disallows moral beliefs, it allows beliefs about more commonly violent passions, because we can distinguish a calm passion from a violent one of the same kind. If I imagine a bear in my garden, then Hume's account suggests I will feel some, presumably very calm, fear. I will also believe that I would feel a more violent fear if there was a bear in my garden. This belief is therefore distinguishable from my impression of fear, so both can exist simultaneously. ${ }^{8}$ However, to approve of a future action or distant character is to have an impression as calm as any approbation one might believe one would experience. This impression differs from the belief only in its level of vivacity, so the two cannot exist simultaneously.

As a final point, Hume's theory does allow that we can entertain non-believed ideas of virtue and vice, and even believed ideas of approbation and disapprobation. If I believe that 'the monks perversely believed that silence was a virtue', then I form a vivid idea of their approbation as caused by silence; I believe that they take silence to be 
virtuous. Further, I can imagine approving of silence, so that I imagine that silence is a virtue. In both cases, because I do not approve of silence, I experience no simultaneous impression of approbation, and I form no belief about the virtue of silence. However, if I come to approve of silence, then I will experience approbation, so that, according to the Vivacity Thesis, I will be unable to form a vivid idea of my own approbation as caused by silence. I will be unable to believe in the virtue of silence. ${ }^{9}$ No doubt this aspect of Hume's theory seems counterintuitive, perhaps startlingly so, to readers today.

Here, we must simply acknowledge that Hume is working with a theory of mind, and especially of belief, which is radically different to any commonly held today. For Hume, our capacities to perceive, believe, desire, imagine and so on are to be explained in quite different ways from one another. There is no reason to think, on Hume's account, that the fact that we can perceive or imagine something must mean that we could believe it, even in principle.

Given his general theory of ideas, Hume has developed a coherent and detailed emotivist account. Admittedly, it is unclear how he might understand some sentences containing moral terms. For example, Blackburn (1998 p. 74) provides a non-cognitivist interpretation of the sentence 'If an act creates happiness then it is good', as 'voicing a certain standard', such that the speaker is 'disposed to value things on the basis that they create happiness'. Perhaps Hume has the resources to form a similar account of such sentences, but he certainly never provides any such account. However, to give a fully satisfactory account along these lines would be to resolve the notorious 'Frege-Geach problem' of understanding how terms which express emotions (or other conations) operate just as descriptive terms do in complex sentences; a problem which it is unclear that Blackburn or any other non-cognitivist has resolved (Schroeder 2008). Hume's remarkable achievement is to have developed in the $18^{\text {th }}$ century an innovative emotivist 
theory which, if one accepts his general theory of ideas, stands or falls on similar grounds to the sophisticated non-cognitivist theories of the $20^{\text {th }}$ and $21^{\text {st }}$ centuries.

\section{Conclusion}

We can only hope to understand all that Hume has to say about morality by considering all three books of his Treatise. It is crucial to his account of moral judgements that moral sentiments are secondary impressions, and so quite unlike sense impressions in their causal origins. Hume's arguments about the nature of these sentiments and their relation to ideas and reasoning are spread throughout the Treatise.

We saw in Section 4 that, because Hume holds the Causal Thesis, HE1 is true: Hume claims that every moral judgement about an object involves an occurrence of approbation or disapprobation, caused by that object. We saw in Section 5 that, because Hume holds the Vivacity Thesis, HE2 is true: Hume claims that, whenever an object causes an occurrence of approbation or disapprobation, any moral judgement about that object will consist of nothing other than this approbation or disapprobation. Together, these theses demonstrate Hume's emotivism. 


\section{ORCID}

James Chamberlain http://orcid.org/0000-0001-6727-4127

\section{References}

Árdal, P. (1966). Passion and Value in Hume's Treatise. Edinburgh: Edinburgh University Press.

Blackburn, S. (1993). Hume on the mezzanine level. Hume Studies, 19, 273-88

Blackburn, S. (1998). Ruling Passions. Oxford: Oxford University Press.

Boehm, M. (2013). The Normativity of Experience and Causal Belief in Hume's Treatise. Hume Studies, 39, 203-31

Bricke, J. (1996). Mind and Morality: An Examination of Hume's Moral Psychology. Oxford: Oxford University Press.

Cohon, R. (2008). Hume's Morality: Feeling and Fabrication. Oxford: Oxford University Press.

Dauer, F. (1999). Force and Vivacity in the Treatise and the Enquiry. Hume Studies, 25, $83-100$

Flew, A. (1966). 'On the Interpretation of Hume.’ In V. C. Chappell (Ed.), Hume: A Collection of Critical Essays (pp. 278-86). Garden City: Doubleday

Garrett, D. (1997). Cognition and Commitment in Hume's Philosophy. New York: Oxford University Press.

Garrett, D. (2015). Hume, New York: Routledge.

Harrison, J. (1976). Hume's Moral Epistemology. London: Oxford University Press

Hume, D. (1978). A Treatise of Human Nature (2 ${ }^{\text {nd }}$ ed.). Edited by L. A. Selby-Bigge. Oxford: Oxford University Press. 
Hume, D. (2000). A Treatise of Human Nature. Edited by David Fate Norton and Mary J. Norton. Oxford: Oxford University Press.

Hume, D. (1975). Enquiries concerning the Human Understanding and concerning the Principles of Morals. Edited by L. A. Selby-Bigge, revised by P. H. Nidditch, Oxford: Clarendon Press.

Hume, D. (2006). An Enquiry concerning the Principles of Morals. Edited by T.L. Beauchamp, Oxford: Oxford University Press.

Mackie, J. L. (1980). Hume's Moral Theory. London: Routledge and Kegan Paul.

Owen, D. (1999). Hume's Reason. Oxford: Oxford University Press.

Penelhum, T. (1975). Hume. London: Macmillan Press Ltd.

Persson, I. (1997). Hume - Not a 'Humean' about Motivation. History of Philosophy Quarterly, 14, 189-206

Pigden, C. (2007). Hume, Motivation and 'The Moral Problem'. In Mazza and Ronchetti (Eds.), New Essays on David Hume. Milano, Franco Angeli, 199-221 Radcliffe, E. S. (1999). Hume on the Generation of Motives: Why Beliefs Alone Never Motivate. Hume Studies, 25, 101-22

Schroeder, M. (2008). What is the Frege-Geach Problem? Philosophy Compass 3, 70320

Snare, F. (1975). The Argument from Motivation. Mind, 84, 1-9

Stroud, B. (1977). Hume. Oxon: Routledge and Kegan Paul.

Sweigart, J. (1964). The Distance Between Hume and Emotivism. The Philosophical Quarterly, 14, 229-36

Waxman, W. (1994). Hume's Theory of Consciousness. Cambridge: Cambridge University Press. 
${ }^{1}$ I do not intend to compare Hume's view with those of the $20^{\text {th }}$ Century emotivists. As Sweigart (1964) notes, Hume's understanding of moral judgements is based on theories of reasoning and passions which are very different from theirs. It is Hume's theory which interests me here.

${ }^{2}$ A Treatise of Human Nature is cited by ' $\mathrm{T}$ ' followed by book, part, section, paragraph, and 'SBN' with the page in the Selby-Bigge edition. An Enquiry concerning the Principles of Morals is cited by 'EPM', followed by section and paragraph, and 'SBN' with the page in the Selby-Bigge edition.

${ }^{3}$ For a detailed argument to this effect, see Owen (1999), chapter 7.

${ }^{4}$ My thanks to an anonymous reviewer for stressing the importance of this claim.

${ }^{5}$ I am grateful to an anonymous reviewer for stressing the importance of this point.

${ }^{6}$ However, see Radcliffe (1999) for an opposing interpretation.

${ }^{7}$ My thanks to an anonymous reviewer for pressing this potential worry

${ }^{8}$ I am grateful to an anonymous reviewer for raising the parallel with fear and suggesting the scenario discussed here.

${ }^{9}$ My thanks to an anonymous reviewer for pressing me on the possibility of non-believed ideas of virtue, and for suggesting the 'monks' example. 